\title{
Bioética y psicoterapia. ¿Cuáles supuestos morales actúan cuando ejecutamos un acto psicoterapéutico?
}

\author{
G ustavo Figueroa C. \\ Bioethics and psychotherapy: \\ Which moral assumptions sustain \\ psychotherapeutical acts?
}

Background: Since about 1970 biomedical ethics crystallized into a full-fledged discipline. The so called «ethical turn»is a fundamental conceptual challenge for the field of medicine and has generated heated controversy. Today, the ancient psychotherapeutic framework is under the severest strain in its long history. Aim: To review the relationship between psychotherapy and the conceptual shift in moral theory. Material and method: To forge a new model for the patient-physician relationship, speech acts and nature of man derived from a pragmatic turn» of bioethics. Results: Research findings suggest that behavior, cognitive and psychodinamic psychotherapies are speech-acts constituted by a hierarchy of subordinate acts distributed on three levels: the level of the locutionary act, the act of saying; the level of the illocutionary act (or force), what we do in saying; and the level of the perlocutionary act, what we provoke by the fact that we speak. Conclusions: Advances in linguistic research have led to a more sophisticated understanding of how psychotherapy affect ethical issues. These developments point towards a new era of psychotherapeutical theory and practice in which specific modes of psychotherapy can be designed to target specific dilemmas of medical ethics (Rev Méd Chile 2004; 132: 243-52).

(Key Words: Bioethics; Ethics, medical; Linguistics; Psychotherapy)

Recibido el 9 de octubre, 2003. Aceptado el 3 de noviembre, 2003.

Departamento de Psiquiatría, Escuela de Medicina, Universidad de Valparaíso.

¿TIENE LA CURACIÓN POR LA PALABRA

UN PUESTO ESPECIAL EN LA BIOÉTICA?

La psicoterapia ha tenido escaso eco en la copiosa productividad bioética de revistas, textos y códigos dedicados al tema. Sus temas controvertidos se han

Correspondencia a: Gustavo Figueroa C. Casilla 92-V. Valparaíso, Chile. Fono/Fax: 5632 508550. E mail: gufigueroa@terra.cl centrado en trasgresión de límites sexuales y no sexuales, consentimiento informado, negligencia y daño, pérdida de la confidencialidad, indoctrinamiento, falta de competencia técnica, y honestidad e ideología en la entrega de datos en la investigación ${ }^{1,2}$. Resulta llamativo el descuido porque, en cualquier relación médico-paciente, se ejecutan actos psicoterapéuticos aunque no configuren una psicoterapia formal, por lo que se han estandarizado como manejo clínico»en el estudio modelo del 
National Institute of Mental Health (NIMH) de la depresión (procurar apoyo y estímulo, consejo directo en caso necesario, etc. ) $^{3,4}$. Pensamos que se debe en parte importante a la ubicación especial que le cabe dentro de las «ecnologías del cambio»y sus intereses»inherentes a la medicina ${ }^{5}$.

Primero, la psicoterapia es una tecnología racional-teleológica -sea instrumental 0 estratégica-, destinada primariamente hacia una meta, que elige sus medios y calcula las consecuencias, dominando la naturaleza, sea orgánica o de las funciones psicológicas (su éxito consiste, por ejemplo, en que el sujeto modifique su temor frente a los espacios abiertos desensibilizándose ante las condiciones evocadoras mediante estrategias sustentadas en el saber empírico). Segundo, también es una tecnología comunicativa o simbólicamente mediada, enfocada a lograr acuerdos con el paciente para coordinar actividades gracias a la reorientación de los fines consecutivo a nuevas definiciones 0 sentidos de la situación (así, la agorafobia no significa que se va a morir de un infarto al corazón sino representa sacar conclusiones precipitadas sobre sus molestias orgánicas sin disponer de datos suficientes que las apoyen) ${ }^{6}$. Finalmente es una tecnología del yo, que comporta un cierto desciframiento de uno mismo», esto es, un «cierto número de operaciones en el propio cuerpo, en el alma, en los pensamientos, en la conducta, de modo tal que se transforma a sí mismo» (saberse agorafóbico conlleva admitir la presencia hasta ahora ignorada, en el interior de uno, de pulsiones eróticas edípicas y exhibicionistas) ${ }^{7}$. Mientras la primera tecnología, la psicoterapia la comparte con los otros métodos para sanar de la medicina (cirugía, dietética, etc.), son las segunda y tercera las que la fundamenta y define en su naturaleza. Los actos psicoterapéuticos son procesos simbólicos a través de los cuales el médico y el paciente se ocupan del sí (soi, self), se redescubre éste a sí, se modifica y reconstruye a sí mismo.

La psicoterapia como tecnología del yo pertenece al ámbito histórico griego y romano de los siglos II y III que Foucault denominó eel ocuparse de uno mismo»(epimeleia heatou, cura sui), a la tradición de «a reflexión acerca de los modos de vida, las elecciones de existencia, la manera de regular su conducta y de fijarse uno mismo fines y medios». Esta preocupación de sí o inquietud por sí va, por tanto, más allá del «conócete a ti mismo» del oráculo del Delfos, puesto que el «uno mismo» no es un objeto enteramente dado que, antes que cualquier otra cosa, es preciso «conocer». Es que la psicoterapia es más que un conocer, es un conjunto de operaciones que permiten, con la ayuda del otro, el objetivo no de descubrir, sino de rechazar lo que se es. Son prácticas» entendidas como modos de actuar y a la vez de pensar que dan la clave de inteligibilidad para la modificación, liberación y nueva constitución del enfermo; es un trabajo conjunto de búsqueda y de transfiguración extendido en el curso del tiempo ${ }^{9}$.

Porque es una tecnología que obedece a tres racionalidades distintas -instrumental-estratégica, consensual-comunicativa o simbólica y hermenéutica ${ }^{6,10_{-}}$, los supuestos bioéticos de cada acción psicoterapéutica ocupan un lugar especial al interior de los procedimientos curativos de la medicina. Queremos limitar nuestro estudio a tres problemas centrales: relación psicoterapeuta-paciente, la psicoterapia como acto de habla y las concepciones del hombre a la base de las psicoterapias.

\section{UNA BREVE HISTORIA CLINIICA}

Un caso cotidiano seguido de algunas intervenciones psicoterapéuticas concretas ayudarán a visualizar el procedimiento de análisis ético. Se trata de Alejandra, 22 años, soltera, estudiante universitaria. Apegada a su padre, se enfrasca en interminables peleas con su madre. Muy buena alumna, disciplinada, nunca ha tenido una relación de pareja. Empezó a preocuparse por su figura corporal e inició una estricta campaña para bajar de peso, que culminó en comer sólo alimentos bajos en calonías y siguiendo un ritual inmodificable en la mesa. Se provoca vómitos, se pesa tres veces al día, usa laxantes, bebe grandes cantidades de líquido, se mide partes de su anatomía (pechos, caderas, muslos, cintura). Piensa constante e inintermumpidamente en su supuesto sobrepeso. Se siente vigilada por sus padres y ha decidido comer sola, aunque prepara a sus familiares ricos platos y los obliga a comerlos. Una ansiedad súbita se apodera de Alejandra y tiene que engullir todo lo que está a su alcance. No acepta en ningún momento haber alcanzado un límite de peso peligroso (42 kilos). Sus menstruaciones comenzaron a espaciarse. Los meses previos surgió un posible pretendiente en su universidad. 
La relación psicoterapeuta-paciente. Las intervenciones psicoterapéuticas para tratar a Alejandra pueden ser muy variadas (Tabla 1). Estas proposiciones obedecen a tres variedades de psicoterapia formal -conductual, cognitiva y psicodinámica-, aunque se pueden encontrar también en distinta proporción en otras situaciones clínicas y en diferentes tipos de tratamiento (Tabla 2). Los tres

Tabla 1. Intervenciones psicoterapéuticas en un trastorno alimentario

1. «Mientras usted come no debe estar ejecutando otras actividades (ver TV, escuchar su música favorita, conversar por teléfono, etc.)».

2. Es importante que inmediatamente después de comer planifique una entretención o esparcimiento que la mantenga ocupada».

3. «iene que comprometerse a llenar meticulosa y diariamente en una cartilla todo lo que come y a las horas que lo hace, tal como se lo he explicado».

4. ¿Siempre piensa entre extremos, o que es una niña perfecta o que es un desastre y no la van a querer nunca más».

5. «esulta que cada vez que obtiene bajar medio kilo se le ocurre que es una simple casualidad y que le va a suceder una especie de catástrofe, que no sólo lo va a volver a recuperar los próximos días sino que va a engordar más aún».

6. «Apenas le asalte la idea que por haber subido 200 gramos usted no vale nada, es necesario que lo autoevalúe para que cuestione su validez».

7 « lo mejor no se ha percatado que sus necesidades de recibir cariño son enormes y por ello queda siempre insatisfecha al terminar cada sesión».

8. «Noto que cada avance suyo parece ir seguido de un sentimiento de culpa porque, en lugar de alegrarse, comienza a reprocharse lo mala hija que ha sido con su madre por las constantes preocupaciones que le produce».

9. ¿a rabia que ve en mí porque no le alabé su manera de manejarse con su pareja me parece que la lleva desde hace tiempo frente a los varones mayores».

Tabla 2. Variedades de psicoterapia formal

\begin{tabular}{|c|c|c|}
\hline Conductual & Cognitivo & Psicodinámico \\
\hline $\begin{array}{l}\text { Síntomas son hábitos } \\
\text { desadaptativos y conductas } \\
\text { productoras de angustia y escape }\end{array}$ & $\begin{array}{l}\text { Distorsiones cognitivas del } \\
\text { yo y mundo con supuestos } \\
\text { básicos disfuncionales de sí }\end{array}$ & $\begin{array}{l}\text { Síntomas son formaciones } \\
\text { simbólicas de conflictos } \\
\text { infantiles inconscientes }\end{array}$ \\
\hline $\begin{array}{l}\text { Respuesta anormal frente a } \\
\text { estímulos y condicionamientos } \\
\text { del medio ambiente }\end{array}$ & $\begin{array}{l}\text { Procesamiento anómalo de la } \\
\text { información que condiciona } \\
\text { emociones y conductas anómalas }\end{array}$ & $\begin{array}{l}\text { Regresión a etapas preedípicas } \\
\text { y agresivas con predominio } \\
\text { del proceso primario }\end{array}$ \\
\hline $\begin{array}{l}\text { Reprogramación, reforzamiento } \\
\text { e inhibición sistemática }\end{array}$ & $\begin{array}{l}\text { Identificación del pensar } \\
\text { automático y cambio del } \\
\text { procesar y concepto de sí }\end{array}$ & $\begin{array}{l}\text { Descubrir el sentido y hacer } \\
\text { consciente lo inconsciente }\end{array}$ \\
\hline $\begin{array}{l}\text { Soluciona problemas, dirige, } \\
\text { ordena, da pautas, reglamenta, } \\
\text { indoctrina, entrega directrices }\end{array}$ & $\begin{array}{l}\text { Señala, conmina, desafía, } \\
\text { programa, enseña, compromete, } \\
\text { reatribuye, invita, informa, } \\
\text { sirve de modelo }\end{array}$ & $\begin{array}{l}\text { Interpreta, elabora, es espejo, } \\
\text { guarda anonimato, es neutral, } \\
\text { sin deseos ni recuerdos }\end{array}$ \\
\hline
\end{tabular}


enunciados primeros son (preponderantemente y cuando se emplean de forma sistemática) conductuales, los segundos son cognitivos y los tres últimos psicodinámicos.

Cada acto psicoterapéutico concreto, al ser expresión directa de una teoría, genera y, a la vez, representa una modalidad de interacción. A partir de Grecia la relación médico-paciente supuso una concepción moral implícita que obedeció al principio de beneficencia ${ }^{11}$. Su paternalismo ingente hizo necesario que la medicina contemporánea entrara en un período dominado por la autonomía y voluntariedad del enfermo ${ }^{12}$. Producto de este giro crucial el vínculo cambió, lo que facultó a que se propusieran los modelos ingenieril, sacerdotal, contractual y de colegas como subtipos específicos de los dos principios bioéticos (Tabla $3)^{13}$. Ahora bien, resulta que las 3 intervenciones cognitivas oscilan entre los modelos ingenieril y sacerdotal; las 3 cognitivas, entre el de colegas y el contractual; y por fin en las 3 psicodinámicas, predominan el del contractual sobre el de colegas.

Esto significa que los modelos no son totalmente satisfactorios cuando se entra a analizar con minuciosidad cada una de las intervenciones. Sin embargo, lo crucial es que históricamente hemos ingresado a una nueva etapa en la bioética que tiene como paradigma de la relación el consentimiento informado, en que el paciente adquiere el derecho a la «decisión responsable». Siguiendo a Gracia, podemos plantear que se ha superado (e incorporado) los niveles anteriores, lo que, para nuestro propósito, permite construir modelos más complejos que consideren mayor número de variables morales -informativo, paternalista, deliberativo, interpretativo (Tabla 4)14-16. EJ Emanuel, artífice de la propuesta, agrega que cada uno se debe validar midiendo su respeto a las seis «C»que preserva cualquier lazo terapéutico: competencia, comunicación, compasión, continuidad, (sin) conflicto de intereses y elección (choice) ${ }^{17}$. Los 3 enunciados conductuales se adecuan mejor al informativo y al paternalista; los 3 cognitivos, al deliberativo; los 3 psicodinámicos, al interpretativo.

Con esa conclusión uno se podría dar por satisfecho porque permite entender coherentemente el caso de Alejandra y potenciales actos psicoterapéuticos de diferentes orientaciones teóricas (o complementarse con otros modelos afines, como el que plantea los tipos libertario, paternalista, beneficencia-en-sustitución, acomodación, psicodinámico) ${ }^{18}$. Lo que resulta llamativo es que los Emanuel, a continuación de analizar las ventajas y objeciones de cada uno, se decidan por el deliberativo como paradigma de referencia», aunque admitan que los demás son útiles en determinadas situaciones clínicas (emengencias

Tabla 3. Ética médica y modelos de relación psicoterapeuta paciente*

\begin{tabular}{|c|c|c|c|}
\hline Ingenieril & Sacerdotal & De colegas & Contractual \\
\hline Hechos y no valores & $\begin{array}{l}\text { Producir el bien y no } \\
\text { dañar }\end{array}$ & Confianza e igualdad & $\begin{array}{l}\text { Compartir } \\
\text { responsabilidades }\end{array}$ \\
\hline $\begin{array}{l}\text { Presentar los datos y } \\
\text { que el paciente } \\
\text { determine }\end{array}$ & $\begin{array}{l}\text { Preservar la dignidad y } \\
\text { valor humanos }\end{array}$ & $\begin{array}{l}\text { Comunidad de intereses } \\
\text { y metas }\end{array}$ & $\begin{array}{l}\text { Paciente mantiene el } \\
\text { control de la decisión } \\
\text { final }\end{array}$ \\
\hline $\begin{array}{l}\text { Psicoterapeuta suspende } \\
\text { sus propios juicios de } \\
\text { valor }\end{array}$ & $\begin{array}{l}\text { Psicoterapeuta conduce } \\
\text { hacia el bien }\end{array}$ & $\begin{array}{l}\text { Psicoterapeuta } \\
\text { comprometido con la } \\
\text { igualdad y respeto }\end{array}$ & $\begin{array}{l}\text { Psicoterapeuta negocia } \\
\text { valores y obligaciones }\end{array}$ \\
\hline Protege libertad personal & Mantiene las promesas & Dice la verdad & $\begin{array}{l}\text { Preserva la dignidad } \\
\text { individual }\end{array}$ \\
\hline
\end{tabular}

*Elaborada y ampliada a partir de Veatch RM (1991). 
Tabla 4. Modelos de relación psicoterapeuta-paciente y bioética informada*

\begin{tabular}{|c|c|c|c|}
\hline Informativo & Paternalista & Deliberativo & Interpretativo \\
\hline $\begin{array}{l}\text { Valores de los pacientes } \\
\text { Definidos, fijos } \\
\text { y conocidos por el } \\
\text { paciente }\end{array}$ & $\begin{array}{l}\text { Objetivos y } \\
\text { compartidos por } \\
\text { terapeuta y paciente }\end{array}$ & $\begin{array}{l}\text { Abiertos a revisión } \\
\text { y desarrollo por la } \\
\text { discusión moral }\end{array}$ & $\begin{array}{l}\text { Incoados, } \\
\text { conflictivos, } \\
\text { requieren } \\
\text { elucidación } \\
\text { permanente y } \\
\text { repetida }\end{array}$ \\
\hline $\begin{array}{l}\text { Obligaciones y deberes del } \\
\text { Dar información } \\
\text { fáctica e implementar } \\
\text { la intervención del } \\
\text { paciente }\end{array}$ & $\begin{array}{l}\text { sicoterapeuta } \\
\text { Promover bienestar } \\
\text { independiente de } \\
\text { preferencias del } \\
\text { paciente }\end{array}$ & $\begin{array}{l}\text { Persuadir sobre } \\
\text { valores admirables } \\
\text { e implementar sus } \\
\text { intervenciones } \\
\text { seleccionadas }\end{array}$ & $\begin{array}{l}\text { Elucidar e } \\
\text { interpretar los } \\
\text { valores } \\
\text { relevantes e } \\
\text { implementar sus } \\
\text { Intervenciones } \\
\text { seleccionadas }\end{array}$ \\
\hline $\begin{array}{l}\text { Autonomía del paciente } \\
\text { Elección y control } \\
\text { sobre el cuidado } \\
\text { médico }\end{array}$ & $\begin{array}{l}\text { Asentimiento de los } \\
\text { valores objetivos }\end{array}$ & $\begin{array}{l}\text { Autodesarrollo } \\
\text { relevante al cuidado } \\
\text { médico }\end{array}$ & $\begin{array}{l}\text { Autocomprensión } \\
\text { relevante al } \\
\text { cuidado médico }\end{array}$ \\
\hline $\begin{array}{l}\text { Concepción del rol del psic } \\
\text { Técnico experto } \\
\text { competente }\end{array}$ & $\begin{array}{l}\text { erapeuta } \\
\text { Guardián, conductor o } \\
\text { supervisor }\end{array}$ & $\begin{array}{l}\text { Amigo, colega o perito } \\
\text { no intrusivo }\end{array}$ & $\begin{array}{l}\text { Intérprete o suerte } \\
\text { de espejo empático }\end{array}$ \\
\hline
\end{tabular}

*Modificada de Emanuel EJ, Emanuel LL (1992) y Hope T, Savulescu J, Hendrick J (2003).

médicas, contactos únicos propio de los policlínicos, cuando existen valores en conflicto) ${ }^{15}$. Con ello queda en claro las dos insuficiencias radicales de este modo de proceder en la ética médica. Por una parte, la interacción psicoterapeuta-cliente se entiende como un fenómeno que posee una esencia definida e invariable, y que se expresa en numerosas dimensiones distintivas (de ahí que rivalicen los modelos como si representaran contenidos incompatibles de una naturaleza unitaria), y no como un intercambio interpersonal dinámico -conductas, palabras, decisiones- que se configura progresivamente a medida que fuerzas opuestas, que provienen por igual de ambos actores, se acomodan y, por consenso, terminan por imponerse unas sobre otras ${ }^{19}$. Por otro lado y más importantemente, los actos psicoterapéuticos no solamente enuncian o describen, no se reducen a presentar el estado de los hechos al paciente, sino, como se mencionó antes, están destinados a transformar al sujeto, son prácticas que cuestionan el ser de la existencia para abrir un camino hacia la sanación, por medio de diferentes procedimientos, provocando el cambio interior y externo ${ }^{20,21}$. Esta impugnación nos conecta con el siguiente apartado.

La psicoterapia como acto de habla. Si Gracia estuviera en lo correcto al decir que hemos entrado en la era del paradigma del consentimiento informado, la psicoterapia consistiría en: a) revelación de una información (sustancial y suficiente para un sujeto promedio); b) a un paciente que es competente (razona, delibera, se comuni- 
ca, posee un conjunto de valores personales); c) éste comprende el material trasmitido; d) voluntariamente toma una decisión (acepta, rechaza, posterga), e) aunque al psicoterapeuta parezca irrazonable o contrario a los mejores intereses de aquel ${ }^{22}$. De acuerdo a la pragmática lingüística correspondería a un acto locucionario o ejecutivo: acción de pronunciar una frase gramaticalmente correcta y cuyo contenido tiene sentido, sel acto de decir algo 23 . Por ello se juega en el plano verdad/falsedad (truth values), que se verifica en la realidad gracias a procedimientos objetivos y empíricos.

Empero no basta esta caracterización, porque se necesita saber siempre y al mismo tiempo el modo en que se usa la locución. Realizar una psicoterapia es efectuar actos ilocucionarios: con iguales palabras, se puede spreguntar», «dar una orden", «hacer una advertencia», 〈amonestar», spersuadiry, etc. Dicho de otra forma, el acto locucionario posee en cada ocasión una determinada fuerza ilocucionaria: la fuerza de un mandato, de una interrogación, etc. Aquí el contexto y el uso determinan si lo dicho es, no verdadero ni falso, sino afortunado o desafortunado (infelicities), si funciona 0 no está en orden. Por último, la palabra curativa es un acto perlocucionario: los efectos que pueden originarse en el otro tras disuadir, obligar..., tal como ser convencido, ejecutar una orden, estarse quieto, saberse apoyado, etc 24 .

Las consecuencias que se desprenden de esta concepción del discurso psicoterapéutico como un momento del «hacer» del médico son variadas. Primero, el paradigma de la psicoterapia como ¿deas que se expresan»se muta en el «decir como acción» apunta a, o inaugura un acto. Además, el diálogo empíricamente observable, se convierte en comunicación intersubjetiva con resultados tanto en el terapeuta (emisor) como el paciente (interlocutor). Tercero, la finalidad primera no es la emisión de contenidos comprensibles (referencias), sino un quehacer destinado a usarse hacia una meta (fuerza ilocucionaria). Por último, en lugar de la verdad verificable y abstracta se busca provocar la verdad en el paciente (efecto perlocucionario $)^{25}$.

Lo interesante para nuestro tema es que las proposiciones psicoterapéuticas, entendidas ahora como realizaciones de 〈actos» y producción de 〈efectos» en el paciente -y no simples «datos» notificados al sujeto-, son orientaciones para las acciones o indicaciones para las prácticas de éste, esto es, adquieren una fuerza»moral que depende de las circunstancias en que se usan. Para entender mejor esta aseveración es necesario situarla como culminación de la tercera etapa del desarrollo histórico de la ética médica. En la Grecia clásica, Aristóteles había distinguido entre saberes teóricos o descriptivos, saberes productivos o técnicos, y saberes prácticos o aplicados al esclarecimiento de la vida corriente; la medicina se ubicaba dentro de estos dos últimos, puesto que tiene por objeto tomar decisiones y ejecutar acciones correctas en situaciones irrepetibles de acuerdo a la recta razón ${ }^{26,27}$. Ahora bien, el médico como técnico tenía que saber tanto hacer bien (pericia o habilidad) como saber por qué lo hacía (con conocimiento de causa o razón de ser); pero, junto a ello, debía decidirse por un curso particular de acción y para ello requería prudencia o phrónesis: era ético porque precisaba ser prudente en sus quehaceres $^{28}$. El Juramento de Hipócrates nació bajo el alero de estas premisas, lo que significa que entregaba pautas de actuar correcto en la vida profesional, que siempre es incertidumbre, es un conocimiento que podría ser de otra manera 29 . El conducirse médicamente (técnicamente) lleva implícito una inteligencia no-técnica (ética) que guía el obrar: este es uno de los motivos por el que la medicina antigua era un arte mudo, muta ars cirugía, dietética, fármacos, etc ${ }^{30}-$. La segunda etapa surge dos mil quinientos años después con el «giro ético» de la bioética que consistió en hacer explícito lo que hasta entonces era sobreentendido: que toda práctica médica, además de técnica, es invariablemente un acto ético, necesita justificarse y supone responsabilidad moral ${ }^{14}$. Ahora entramos en el tercer período que transfigura el ejercicio clínico (recetar un medicamento, ejecutar una cirugía, indicar una tomografía) en un sactuar dialogante»-y que por ello denominamos el sgiro pragmático», lo que lleva consigo que en cada ocasión es una acción psicoterapéutica, versión moderna de los lógi kaloí o Łellos discursos» de Platón, y, como tal, es un hacer ético, posee una potencia moral intrínseca ${ }^{31}$.

En el caso de Alejandra, las 3 proposiciones conductuales, 3 cognitivas y 3 psicodinámicas, son producto de tres teorías psicoterapéuticas. Si se las 
analiza como acciones esencialmente distintas entre sí porque apuntan a atributos del ser humano diferentes iobedecen a diversas concepciones de la moral? Parece claro que las intervenciones conductuales suponen la existencia de una moral natural, por tanto, siguen el orden dictaminado por la realidad material o «isiológica». Por su parte, las cognitivas obedecen las reglas universales propias de la razón humana. Por último, las psicodinámicas se atienen con estrictez a una moral idiosincrática, a dictámenes personales e intransferibles, que nacen de la intimidad libre del enfermo ${ }^{27}$. En la Tabla 5, anotamos unas cuantas intervenciones de las tres corrientes, sabiendo de antemano que Austin no se cansó de advertir que verbos que denoten actos ilocucionarios hay más de un millar en inglés ${ }^{23}$.

En otras palabras, la psicoterapia es un especial juego de lenguaje», como lo denominaba Wittgenstein, bastante más rico y sutil que lo que se plantea por lo regular en los tratados teóricos dedicados al tema. Ella hace uso de distinciones afinadas que van más lejos que los huidizos matices de lo vivido, como si en el lenguaje que utiliza se hubiesen cristalizado y sedimentado múltiples experiencias de vida, lo que exige que los análisis esbozados hasta aquí necesiten, por cierto, ser reelaborados con bastante mayor prolijidad y detenimiento ${ }^{32}$. Por mencionar un complemento, se podrían perfeccionar con los aportes de
Laín tomados de Karl Bühler de su teoría del lenguaje ${ }^{33}$. En el último punto de la tabla insinuamos las concepciones del hombre que sostienen cada moral, lo que nos pone en relación con el siguiente apartado. Allí encontraremos las bases que sustentan y explican el conjunto de nuestro análisis.

Concepciones del hombre. La psicoterapia nace tímidamente en Grecia (psicoterapia empíricofilosófica), se desarrolla con celeridad a partir del Romanticismo y especialmente el Positivismo de finales del siglo XIX con Freud (psicoterapia científica), y sufre un viraje revolucionario a comienzos de los años 60 (psicoterapia validada) ${ }^{30,34,35}$. Coincide aproximadamente con tres ideas fundamentales de la ética y, por consiguiente, con tres ideas del hombre: ética de la era del «ser», ética de la era de la «conciencia»y ética de la era del «enguaje»-hombre como ente natural, hombre como ente pensante 0 conciente, $\mathrm{y}$ hombre como ente lingüístico-.

Este paralelismo de curso apunta a una comunidad conceptual profunda a la base que la bioética ha asumido y que se expresa, por su parte, en los períodos de beneficencia, autonomía y consentimiento informado (o, como hemos propuesto más arriba siguiendo el giro pragmático propio de la psicoterapia, ¿comunicación consensuada?, ¿interlocución argumentativa?, ¿diálogo co-

Tabla 5. Intervenciones psicoterapéuticas, moral básica y ser del hombre

\begin{tabular}{|c|c|c|c|}
\hline & Conductual & Cognitivo & Psicodinamia \\
\hline Intervenciones & $\begin{array}{l}\text { Ordenar, prohibir, } \\
\text { amonestar, dictaminar }\end{array}$ & $\begin{array}{l}\text { Señalar, constatar, } \\
\text { reatribuir, enfatizar }\end{array}$ & $\begin{array}{l}\text { Interpretar, transelaborar, } \\
\text { clarificar, confrontar }\end{array}$ \\
\hline Moral a la base & Moral natural & Moral universal & $\begin{array}{l}\text { Moral idiosincrásica o } \\
\text { propia }\end{array}$ \\
\hline Fundamento moral & Ley natural & $\begin{array}{l}\text { Leyes de la razón } \\
\text { humana }\end{array}$ & $\begin{array}{l}\text { Libertad } \\
\text { Responsabilidad consigo }\end{array}$ \\
\hline Punto inicial & Desconocimiento & Ocultamiento & Falsa comprensión \\
\hline Meta final & Ejecución de su ser & Purificación & Expansión de sí \\
\hline Virtud del paciente & Obediencia & Autoaceptación de sí & Veracidad consigo \\
\hline Virtud psicoterapeuta & Competencia & Competencia & Prudencia \\
\hline $\begin{array}{l}\text { Meta a la que } \\
\text { se dirige la palabra }\end{array}$ & $\begin{array}{l}\text { Naturaleza o Phycis } \\
\text { del ser humano }\end{array}$ & Autoconocimiento & Autorrealización \\
\hline
\end{tabular}


responsable?, ¿inter-acción validada?). Esto es, en distinta medida, la ética médica ha modificado y ampliado importantemente la moral, la filosofía y las teorías antropológicas al generar creativamente principios en consonancia directa con los hallazgos de la realidad clínica, y plantear problemas perentorios e inéditos ${ }^{12,16}$. Tiene razón Gracia cuando afirma que la bioética médica actual, después de treinta años de avance sostenido, ha llegado a sustentar sus principios últimos en una doble premisa: ontológica -el hombre es persona, y en cuanto tal tiene dignidad y no precio- y ética -en tanto que personas, todos los hombres son iguales y merecen igual consideración y respeto ${ }^{14}$. . Su innegable raigambre kantiana y deontológica, no deja de considerar el momento teleológico o consecuencial.

Las tres variedades de psicoterapia utilizadas con Alejandra en cuanto productos de tres teorías específicas, ¿qué concepciones implícitas del ser humano suponen? Al estudiar la Tabla 6, se aprecia de inmediato que el conductismo, el cognitivismo y el psicodinamismo conciben al hombre, respectivamente, como ser natural 0 sujeto que está adscrito al orden físico (physis); como mente que sabe de sí de modo inmediato y unívoco o individuo que es una cosa pensante; y como persona escindida que carece de un centro unitario y definido o ente que inventa su propia identidad acudiendo a narrativas desperdigadas durante su existencia. Estos atributos -si es que son atributos o más bien modos de ser- permiten entender el resto de las características. Frente al accionar siguiendo reglas fisiológicas comunes a la especie se encuentran, por una parte, las unidades de procesamiento que emergen adquiriendo mayor complejidad de acuerdo a la dificultad de la tarea (la psiquis como aparato computacional) y, por la otra, el individuo que no posee nada dado con anterioridad sino, es agente y autor simultáneo de su propia biografía personal e inintercambiable. Cuando se lleva a cabo una intervención psicoterapéutica, ésta actúa, según el caso, como estímulo, como información o como símbolo verbal de un interlocutor válido. A su vez, la primera sigue una racionalidad de acuerdo a las leyes de la naturaleza, la segunda acata las reglas del pensamiento humano, y la tercera se guía por el principio hermenéutico del doble sentido, 0 sea, que el significado explícito lleva oculto uno profundo que es preciso descubrir y develar por medio de la interpretación. Conducir un diálogo conductual consiste en ajustarse a leyes valóricas que son prescritas por el devenir de la naturaleza misma (heteronomía); cognitivamente, permitir que el propio paciente elabore y decida sus normas y virtudes en consonancia con sus datos y experiencias (autonomía); psicodinámicamente, hacer que el enfermo se apropie de sí y sus posibilidades.

Unas palabras finales de cautela. Este somero esbozo deja sin considerar, a propósito, dos cuestiones que son objeto de intenso debate en el pensamiento actual, porque complicaría excesivamente la exposición, aunque, por supuesto, la haría ganar en precisión y hondura. Por una parte, la conciencia como la entiende la filosofía idealista (Kant, Hegel, Husserl) no se superpone sin más

Tabla 6. Concepciones del hombre a la base de tres variedades de psicoterapias

\begin{tabular}{|c|c|c|c|}
\hline & Ser natural & Mente (cognición) & Ser lingüístico \\
\hline Esencia & Ente natural & Conocimiento inmediato de sí & Descentramiento de sí \\
\hline Ser último & $\begin{array}{l}\text { Naturaleza igual y } \\
\text { común }\end{array}$ & $\begin{array}{l}\text { Microcomponentes unitarios } \\
\text { e irreductibles }\end{array}$ & $\begin{array}{l}\text { Sin naturaleza sino } \\
\text { historia }\end{array}$ \\
\hline $\begin{array}{l}\text { Relación } \\
\text { al medio }\end{array}$ & Estímulo-respuesta & Información-respuesta & Interlocutor válido \\
\hline Racionalidad & Racionalidad natural & Racionalidad pura & $\begin{array}{l}\text { Racionalidad } \\
\text { hermenéutica }\end{array}$ \\
\hline \multirow[t]{2}{*}{ Normas } & Normas externas & Normas internas & Normas propias \\
\hline & [Heteronomía] & [Autonomía] & [Autenticidad] \\
\hline
\end{tabular}


con la mente o las cogniciones o la «conciencia» del pensamiento analítico, ciencias neurocognitivas y la filosofía de la mente (mind) ${ }^{36,37}$; un salto entre ontologías radicalmente diferentes confunde antes que ilumina. Por otro lado, el dualismo o el materialismo monista que están implícitos, pero amalgamados sin pulcritud en las posturas psicoterapéuticas, requieren que se precisen con posterioridad algunos de sus asertos que, dichos al pasar, cuando menos resultan ambiguos ${ }^{38,39}$. La relación mente-cuerpo, en este terreno, sigue siendo un misterio» a pesar del optimismo desbordante de Searle: «El famoso problema mentecuerpo, la fuente de tantas controversias durante los dos últimos milenios, tiene una solución muy simple. Esta solución ha estado al alcance de cualquier persona culta... Tal solución es la siguiente: los fenómenos mentales están causados por procesos neuropsicológicos del cerebro y son a su vez rasgos del cerebro... . [En este] naturalismo biológico», los eventos y procesos mentales son parte de nuestra historia natural biológica en la misma medida en que lo son la digestión, la mitosis, la meiosis o la secreción de enzimas ${ }^{40}$.

\section{ConClusiones}

Las relaciones entre psicoterapia y bioética competen por igual a los fundamentos últimos de la medicina, moral y filosofía; son propuestas que, por la complejidad de los saberes involucrados -especulativo y práctico-, deben considerarse como un primer esquema de trabajo. Requieren

\section{REFERENCIAS}

1. Holmes J. Ethical aspects of the psychotherapies. En: Bloch S, Chodoff P, Green S, editors. Psychiatric ethics. $3^{\text {rd }}$ edition. Oxford: Oxford University Press, 1999; 233-4.

2. Dewald PA, Clark RW. Ethics case book of the American Psycoanalytic Association. New York: American Psychoanalytic Association, 2001.

3. SHEA MT, ELKIN I, SotsKY SM. Patient characteristics associated with successful treatment. Outcome de una labor ulterior meticulosa de deslinde y concreción que de cuenta de los matices clínicos, y afine los principios ontológicos. De todas maneras, algunas conclusiones preliminares son útiles para entender las concepciones que están a la base.

1. El «giro ético»que representó la bioética al interior de la medicina y pensamiento contemporáneo, ha sido sucedido por un «giro pragmático»prioridad de la esfera práctica-, dentro del cual está ubicada la psicoterapia. 2. Las etapas de «autonomía»y «consentimiento informado» precisan una refundación en la scomunicación intersubjetiva consensuada»entendida como ejecución o efectuación de acciones enunciativas, como actos de habla. 3. La psicoterapia no es primariamente un hablar sino un comunicar que tiende a una acción, o la inicia, es por tanto una realización o un obrar. Por ello no se juega primariamente en la verdad/falsedad sino en lo acertado/ desacertado o condiciones de éxito. Tiene fuerza, esto es, compromete y modifica al paciente tanto como al terapeuta. 4. Esta rehabilitación del ámbito de lo práctico y reducción de la racionalidad instrumental-estratégica supone que cualquier acción psicoterapéutica conlleva un sentido ético implícito, dado por el enfermo, el psicoterapeuta o el medio sociocultural -principio de contextualidad y del pluralismo-, y que se expresa en lo inmediato en diversas modalidades de relación médico-paciente. 5. Cada variedad de psicoterapia tiene su razón primera en una idea distinta del hombre: ser natural (factum), conciencia y ser lingüístico (faciendum).

findings from the NIMH treatment of depression collaborative research program. En: Janowsky DS, editor. Psychotherapy. Indications and outcomes. Washington: American Psychiatric Press, 1999; 71-90.

4. Figueroa G. Psicoterapia y farmacoterapia en el tratamiento de la depresión mayor. Rev Chil Neuro-Psiquiat 2002; 40 [Suplemento 1]: 7795.

5. HaBERMAS J. Erkenntnis und Interesse. Mit einem neuen Nachwort. Frankfurt: Suhrkamp: 1973. 
6. Habermas J. Theorie des kommunikativen Handelns. 2 Bände. Frankfurt: Suhrkamp, 1981.

7. Foudault M. Technologies of the self. A seminar with Michel Foucault. Amherst: The University of Massachusetts Press, 1988.

8. Foucault M. L'hérmeneutique du sujet. Cours au Collège de France 1981-1982. Paris: Seuil/Gallimard, 2001.

9. Foucault M. Histoire de la sexualité: le souci de soi. Paris: Gallimard, 1984.

10. Ricoeur P. Hermeneutics and the human sciences. Cambridge: Cambridge University Press, 1981.

11. CHIIDRESSJF. Who should decide?: paternalism in health care. New York: Oxford University Press, 1982.

12. BeAuchamp TL, Childress JF. Principles of biomedical ethics. $4^{\text {th }}$ edition. New York: Oxford University Press, 1994.

13. VEATCH RM. Models for ethical medicine in a revolutionary age. En: Mappes TA, Zembaty JS, editors. Biomedical ethics. $3^{\text {rd }}$ edition. New Cork: McGraw-Hill, 1991; 55-8.

14. Gracia D. Bioética clínica. Bogotá: El Búho, 1998.

15. EMANUEl EJ, EMANUEL LL Four models of the physician-patient relationship. JAMA 1992; 267: 2221-6.

16. Hope T, Savulescu J, Hendrick J. Medical ethics and law. The core curriculum. Edinburgh: Churchill Livingstone, 2003.

17. Emanuel EJ, DubleR NN. Preserving the physicianpatient relationship in the era of managed care. JAMA 1995; 273: 323-9.

18. Balnt J, Shelton W. Regaining the initiative. Forging a new model of the patient-physician relationship. JAMA 1996; 275: 887-91.

19. SiEgLER M. The physician-patient accommodation. A central event in clinical medicine. Arch Intern Med 1982; 142: 1899-902.

20. Foucault M. Freiheit und Selbstsorge. Frankfurt: Materialis Verlag, 1985.

21. Gabbard GO, Westen D. Rethinking therapeutic action. Int J Psychoanal 2003; 84: 823-41.

22. FADEN RF, BEAUCHAMP TL A history and theory of informed consent. New York: Oxford University Press, 1986.
23. Austin JL. How to do things with words. New York: Oxford University Press, 1962.

24. SEARLE J. Speech acts. An essay in the philosophy of language. London: Cambridge University Press, 1969.

25. Ricoeur P. Le discours de l'action. Paris: Centre National de la Recherche, 1981.

26. ARISTóteles. Metafísica. 2 volúmenes. Madrid: Gredos, 1970.

27. Cortina A, Martínez E. Ética. 3a edición. Madrid: Akal, 2001.

28. Zubiri X. Cinco lecciones de filosofía. Madrid: Sociedad de Estudios y Publicaciones, 1963.

29. Aristóteles. Ética a Nicómaco. Madrid: Centro de Estudios Constitucionales: 1981.

30. Laín EnTRALgo P. La curación por la palabra en la antigüedad clásica. Madrid: Revista de Occidente, 1958.

31. Platón. Cármides. En: Platón. Diálogos I. Madrid: Gredos, 1981; 317-68.

32. CAmps V. Pragmática del lenguaje y filosofía analítica. Barcelona: Ediciones Península, 1976.

33. Laín EnTRaLgo P. Antropología médica para clínicos. Barcelona: Salvat, 1985.

34. López Piñero JM, Morales Meseguer JM. Neurosis y psicoterapia. Un estudio histórico. Madrid: Espasa-Calpe, 1970.

35. WALLeRSTeIN RS. The talking cures. The psychoanalyses and the psychotherapies. New Haven: Yale University Press, 1995.

36. Searle JR. The mistery of conciousness. New York: New York Review of Books, 1997.

37. D’Agostin F. Analíticos y continentales. Guía de la filosofía de los últimos treinta años. Madrid: Cátedra, 2000.

38. Changeux J-P, Ricoeur P. Ce qui nous fait penser: la nature et la règle. Paris: Éditions Odile Jacob, 1998.

39. KENDLER KS. A psychiatric dialogue on the mindbody problem. Am J Psychiatry 2001; 158: 9891000.

40. Searie JR. The rediscovery of the mind. Cambridge: The MT Press, 1992. 